Review

International Journal of Medical Sciences

ISSN 1449-1907 www.medsci.org 2007 4(2):83-93

(c) Ivyspring International Publisher. All rights reserved

\title{
Rasburicase represents a new tool for hyperuricemia in tumor lysis syn- drome and in gout
}

\section{Lisa Cammalleri and Mariano Malaguarnera}

Dept of Senescence, Urological and Neurological Sciences, University of Catania, Catania, Italy

Correspondence to: Mariano Malaguarnera, A.P., Via Messina 829 - 95125 Catania (Italy). Phone ++39 957262008 ; Fax ++39 957262011 ; E-Mail: malaguar@unict.it

Received: 2007.01.12; Accepted: 2007.03.01; Published: 2007.03.02

Hyperuricemia is a feature of several pathologies and requires an appropriate and often early treatment, owing to the severe consequences that it may cause. A rapid and massive raise of uric acid, during tumor lysis syndrome (TLS), and also a lower and chronic hyperuricemia, as in gout, mainly damage the kidney. To prevent or treat these consequences, a new therapeutic option is represented by rasburicase, a recombinant form of an enzyme, urate oxidase. This enzyme converts hypoxanthine and xanthine into allantoin, a more soluble molecule, easily cleared by kidney. The several types of urate oxidase have followed each other, with progressive reduction of adverse reactions. The most important among them are allergenicity and the development of antibodies which compromise their effectiveness. Nevertheless, a limit of rasburicase's use remains its cost, which obliges to a judicious choice to prevent TLS in high risk patients with cancer and in case of allergy or impossibility to take allopurinol orally both in TLS and in gout. A large body of evidence confirms the efficacy and safety of rasburicase, even in comparison to the standard drugs used in the aforementioned pathologies.

Key words: Urate oxidase, allantoin, rasburicase, hyperuricemia, tumor lysis syndrome, acute renal failure, gout, allopurinol, uric acid

\section{Introduction}

Uric acid is a weak organic acid (pKa 5.8), poorly water-soluble at acidic $\mathrm{pH}$. It derives partly from diet and partly from endogenous biosynthesis and it is eliminated by enteric (25-35\%) and renal $(65-75 \%)$ ways. We define hyperuricemia the uric acid blood level over $8 \mathrm{mg} / \mathrm{dl}(4.76 \mu \mathrm{mol} / \mathrm{l})$.[1] The impact of hyperuricemia is wide felt because it may cause pathologic consequences in several organs, such as kidney, brain, subcutaneous tissue, joints. Many studies underline the direct proportionality between serum urate and risk of gout. [2,3] Hyperuricemia, in fact, is considered its biochemical hallmark, because the precipitation of uric acid is possible when uric acid exceeds the limit of solubility (about $4.20 \mu \mathrm{mol} / 1$ at $37^{\circ}$ C). Gout attack is one of the most painful situations suffered by humans, [4] owing to the crystallization of uric acid within joints with the consequent intermittent attacks of arthritis.

The tophaceous gout is the chronic and insidious evolution that happens after 10 or more years. It is characterized by the deposition of monosodium urate (tophi) in soft tissues around joints, in kidney and in subcutaneous tissue.

Kidney is one of the most involved organs in case of hyperuricemia, because it is the main site of uric acid excretion. Its impairment may be of different types. Hyperuricemia is a cause of urolithiasis. Calculi predominantly composed of uric acid represent around $13 \%$ of human kidney stones. [5]

It is possible also an acute urate nephropathy, due to a dramatic and rapid increase of uricemia and renal handling of uric acid and urate. The crystals precipitate and obstruct tubules of distal nephrons and collecting ducts, where $\mathrm{pH}$ is acidic. The result is a tubular necrosis and acute renal failure (ARF) because of intrarenal obstruction of urinary flow. After the disruption of the tubules, crystals start to accumulate in the interstice. Crystallization is worsened by volume depletion (frequent in neoplastic patients owing to vomiting, diarrhoea, fever), that compromises glomerular filtration and increases urate concentration in distal tubule. Also, low urine $\mathrm{pH}$ reduces uric acid solubility, worsening crystallization. [6]

The most frequent causes of ARF are the cytostatic therapies in patients with cancer or blastic crisis in acute leukaemia. The consequent massive cellular lysis exceeds the renal excretory ability. ARF is reversible with early treatment. Calculi are rarely described in this kind of renal damage.

The last type of renal damage is "gouty nephropathy", occurring when hyperuricemia is persistent but mild. In the interstice and in some tubules we can find precipitated microcrystals, which lead a chronic inflammation, evolving to arteriolosclerosis, tubulo-interstitial fibrosis, glomerulosclerosis [7] and so to chronic renal failure.

Hence, in this paper we review a drug that quickly reduce uric acid levels, especially in emer- 
gency situations, such as tumor lysis syndrome (TLS), and discuss possible options for using this drug also in chronic conditions, such as gout.

\section{Uric acid synthesis}

The starting point of uric acid synthesis is the ribose-5-phosphate, a pentose derived from glycidic metabolism, converted to PRPP (phosphoribosyl pyrophosphate) and then to phosphoribosilamine, that will be transformed into inosine monophosphate (IMP). From this intermediate compound derive adenosine monophosphate (AMP) and guanosine monophosphate (GMP), the purinic nucleotides useful for DNA and RNA synthesis, and inosine that will be degraded into hypoxanthine and xanthine and finally into uric acid.

Hypoxanthine and guanine may enter in a salvage pathway, using hypoxanthine-guanine phosphoribosyltranferase (HGPRT), an enzyme that reconverts these purines bases into respective nucleotides. (Table 1)

In humans and other primates, urate oxidase (uricase), a hepatic enzyme, is inactive as a result of a non-sense mutation, originating a stop codon. So, only animals which possess uricase are able to transform uric acid in a more soluble (5 - 10 times more than uric acid) and more eliminable molecule: allantoin. A side product of this reaction is hydrogen peroxide, toxic for kidney, that is converted in $\mathrm{H}_{2} \mathrm{O}$ and $\mathrm{O}_{2}$ by catalase. A hypothesis considers this mutation as a result of phylogenetic evolution, because uric acid has antioxidant properties, that protect against neurological degenerative diseases, and increases longevity. [8] Yet, the loss of this enzyme arises the consequences derived from uric acid poor solubility. Mice with gene inactivation of urate oxidase have hyperuricemia and renal tubulopathy. [9]

In the past, this alternative metabolic pathway, absent in men, was exploited in order to reduce uric acid levels by making a kind of substitutive therapy. Standard drugs used to prevent and treat hyperuricemia may be burdened by several effects that reduce efficacy and safety.

This objective has been achieved with the synthesis of uricase.

\section{Urate oxidase history}

The first molecule of this kind, synthetized in 1968 and introduced in France since 1975 and in Italy since 1984, was a non-recombinant urate oxidase. [10] It was a natural uricase, obtained from Aspergillus flavus cultures (Uricozyme TM), used to prevent and treat hyperuricemia occurring during chemotherapy. [10]

Its slow and poor production and its scarce purity were the main limits of its use.

Its proteic nature, the poor accurate process of purification and the administration of a molecule, genetically absent in humans, made hypersensitivity reactions very probable, even in patients without history of allergy. Immunogenicity and hypersensitivity, in fact, were due to the great number of impurities in the preparation.
Immunogenicity might have caused the production of antibodies with possible reduction of drug efficacy. Hypersensitivity presented with rashes, bronchospasm, urticaria and angioedema in about $5 \%$ of patients. Allergic reactions occurred within 1-17 minutes after the beginning of the first infusion. [10]

Since 1996, the molecule currently used, rasburicase (Fasturtec ${ }^{\mathrm{TM}}$ in Europe, Elitek ${ }^{\mathrm{TM}}$ in USA) is obtained by recombinant DNA technique. A genetically modified strain of Saccharomyces cerevisiae expresses urate oxidase cDNA, cloned from a strain of Aspergillus flavus. [23] It allows to obtain urate oxidase more rapidly and in a larger quantity. Also, rasburicase is purer with higher activity than non-recombinant urate oxidase. During the production process the molecule and its structure are totally conserved.

A modification of a reactive cysteine, obtained during the purification process of non-recombinant urate oxidase, and the higher purity of rasburicase may explain the differences between the old and the new urate oxidase. [12]

In fact, the old and the new urate oxidase do not significantly differ from a pharmacodynamic point of view; the only difference consists in the reduction of rasburicase's adverse effects. Studies have reported the presence of antibodies antirasburicase in some patients [13], whilst others reported no development of antibodies after several days of therapy.[14]

Four monomers (of a molecular mass of $34 \mathrm{kDa}$ each) form rasburicase, that is currently classified as detoxifying agent for antineoplastic treatment. Its use in other hyperuricemic conditions, such as chronic gout, is difficult, because rasburicase has a short half-life, which requires a daily administration. So, PEGylation technique has been proposed to prolong half-life and further reduce immunogenicity.

The PEGylation consists in binding with a covalent link a protein (adenosine-deaminase, asparaginase, interferons, granulocyte colonystimulating factor, liposomal doxyrubicin) to poly(ethylene) glycol. It permits to obtain molecule with prolonged half-life (terminal half-life between 10-20 days) and thus a weekly administration. The PEGylated form of rasburicase, a bacterial urate oxidase, was used the first time in 1988 to treat a nephropathy induced by uric acid in a case of non-Hodgking lymphoma. [15] Then PEG-uricase was proposed for cases of uncontrolled gout or for intolerance or not compliance to standard therapy. [16] It was a mammalian, recombinant urate oxidase, modified with monomethoxy-PEG. [9] The use of non-modified, recombinant mammalian uricase is impossible, because of its immunogenicity and ineffectiveness in decreasing uric acid levels. [9] Although PEGylation is a process that could reduce hypersensitivity reaction, the development of antibodies has been reported. Nevertheless, it could resolve spontaneously during the treatment. [16]

So, maintaining the same efficacy of rasburicase, the advantages of PEG-uricase may be: lack of antigenicity, absence of side effects and a longer duration of activity. 


\section{Rasburicase pharmacokynetics}

Information about pharmacokinetics derives by the use of rasburicase in children and young adults. Few data are available in adults and elderly. [17]

The distribution volume is similar to the physiological blood volume. It is administered once a day, being the half-life is 19 hours. Steady state is achieved in 2-3 days. Even after 5 days of treatment, a consistent accumulation has not been reported. [13] Interaction studies have been performed in vitro where rasburicase does not show interaction with other drugs. Association between rasburicase and allopurinol should be avoided, because the latter may reduce the effect of rasburicase owing to its inhibition of xanthine oxidase and consequent reduced uric acid concentration. [18]

Studies about metabolism have not been performed but as other protein, rasburicase metabolism occurs by peptide hydrolysis, so liver should not be involved and the cytochrome P450 is not inducted or inhibited; so even hepatic pathologies do not require an adjustment of dosage. [10] Its clearance does not depend on renal function.

\section{Rasburicase pharmacodynamics}

It is an enzyme whose action consists in catalyzing the oxidation of uric acid into allantoin, rapidly excreted by the kidneys. Allantoin is poorly toxic and easy cleared, also in cases of renal impairment. The reaction occurs through an intermediate, 5- hydroxyisourate, that will be converted into allantoin with a non-enzymatic degradation. [19] This reaction releases a molecule of hydrogen peroxide, an oxidant product, that human anti-oxidant system (catalase) neutralizes producing water and oxygen. Subjects with a glucose 6 phosphate dehydrogenase deficiency are lacking in antioxidant systems, so they do not detoxify hydrogen peroxide. Rasburicase is contraindicated in these patients.

Rasburicase recommended dose is 0.20 $\mathrm{mg} / \mathrm{Kg} /$ die diluted in $50 \mathrm{ml}$ of sodium chloride solution $(0.9 \%)$, administered intravenously in 30 minutes, daily or twice daily for 5-7 days. Hence, a large number of studies have tested different doses, even lower than standard dose and for shorter period than recommended. [20] A single dose of rasburicase, at low dosage, has showed a rapid reduction of hyperuricemia. [21-24] Contemporary use of alkalinization, hydration and rasburicase at $0.10 \mathrm{mg} / \mathrm{kg}$ for $3-5$ days maintains the same efficacy. [25] Anyway, we may have favourable issues by changing the dose of rasburicase, according to the various clinical states, the type of malignancy and drugs used. The use of low doses of rasburicase may permit to spare the total cost on the management of patients and to reduce the risk of the development of antibodies.

\section{Clinical use}

\section{Tumor Lysis Syndrome (TLS)}

Already before 2002, when Food and Drugs Administration (FDA) of US has approved the use of urate oxidase for the management of paediatric patients at risk for TLS (Tumor Lysis Syndrome) [26], urate oxidase was used for this purpose with good efficacy. [13,14,27-30] Currently US FDA does not approve its use in adult, instead EU FDA has approved it in children and adult. [19]

Tumor lysis syndrome (TLS) is a spontaneous condition (present in haematological malignancies and other conditions) or, more frequently, occurring in consequence of chemotherapy, radiotherapy or immunotherapy. $[6,19,31]$ It is characterized by massive and rapid cellular lysis with consequent release of intracellular molecules, a condition that raises the risk of morbidity and mortality, even in patients potentially curable. TLS is defined as the presence of at least 2 of the following laboratory data: hyperuricemia, hyperkalemia, hyperphosphatemia, and secondary hypocalcemia as described by Cairo- Bishop criteria. [1] According to these criteria, the levels of these abnormalities must draw away $25 \%$ from baselines or exceed the threshold value showed in table 2. (Table 2)

Hyperuricemia is very common in patients with a neoplastic disease and it is already present at the diagnosis or it develops within 48-72 hours after the treatment.

The greater is the growth rate of tumor, the higher is the content of DNA and consequently of uric acid produced. When uric acid exceeds renal capacity of elimination, it precipitates into renal tubules. So, a vicious circle creates because the consequent renal functional impairment worsens hyperkaliemia and hyperphosphatemia, phosphorus and calcium bind themselves and precipitate within kidneys. (Figure 1)

These metabolic abnormalities are more harmful in neoplastic patients, since their general conditions are already compromised by cachexia, malnutrition, pain. It is an imperative treating or, better, preventing TLS, because each metabolic derangement is associated with remarkable clinical manifestations.

Hyperuricemia and hyperphosphatemia severely worsen renal functionality; hyperkalemia and hypocalcemia compromises regular cardiac rhythm causing arrhythmias, sometimes mortal, and neuromuscular function, with potential tetany, convulsion, cramping. [32] Being the clearance of uric acid, potassium, calcium and phosphate mainly renal, kidneys are overloaded, until their excretion ability is saturated with great difficulties to eliminate electrolytes, toxic substances and drugs, with consequent risk of accumulation and toxicity. Uric acid can determine the renal impairment in different ways: the local and direct obstruction and toxicity on tubules and the local and systemic inflammation. Other factors may contribute to pathogenesis of ARF: the nephrotoxicity of some chemotherapeutic, antibiotics, antiviral and antifungal drugs [25], kidney obstruction or compression or renal vascular thrombosis in solid tumors. (Figure 2) It is necessary to underline that rasburicase controls hyperuricemia, but it has not direct effect on the other metabolic abnormalities, that will be treated with specific measures. 
TLS has been reported in association with several tumors: haematologic malignancies and bulky solid tumours. [32,33-35]

The efficacy of rasburicase in the prevention and treatment of TLS has been studied by several authors who have demonstrated its effectiveness, despite its extremely high cost. A Pan-European multicentre study has weighed the cost-effectiveness ratios of preventing and treating TLS with rasburicase, in haematological malignancies, both in children and adults with the conclusion that rasburicase remains a useful drug clinically effective and in addition with a favourable economic outcome in the treatment of hyperuricemia. In prevention, instead, its cost-effectiveness is favourable in children with all type of haematological malignancies and in adults with acute lymphoblastic leukaemia and non-Hodgkin lymphoma, but lower in acute myeloid leukaemia because of short average life expectancy. [36]

Rasburicase effectiveness and safety should permit us to spare money from the treatment of consequences of cytoreductive treatments and haemodialysis.

Therefore, this drug is effective and safe, $[13,18,20,37-39]$ but because of its cost, its use is justified only in some groups of patients which are at risk for TLS or have TLS and are allergic to allopurinol or cannot ingest it orally. The risk-factors can be related to the tumour or to the subjects with cancer (Table 3 ). $[19,40,41]$ Patients in who we may consider the use of rasburicase, owing to risk of TLS, are those who have hyperuricemia, high tumor burden, high growth rate of tumor, high sensitivity to chemotherapy and renal impairment.

Standard measures to prevent and treat hyperuricemia include allopurinol and alkalinization, associated with an aggressive hydration. Rasburicase presents various features that give it a more favourable profile than standard drugs used for TLS. The classic approach to TLS fails in prevention of acute renal failure in over to $25 \%$ of patients. [42]

\section{Gout}

Even though rasburicase is approved for treatment and prophylaxis of acute hyperuricemia in haematological malignancy with a high tumour burden, in order to prevent acute renal failure, it has been used for other purposes.

Life style changes (resulting in obesity), a protein richer diet, longevity and the use of some drugs (diuretics) have caused an increase of some pathologies, such as gout. It affects at least $1 \%$ of Western population. [43]

Rasburicase may be able to dissolve tophi in therapy-resistant tophaceous gout. [44,45]

Allopurinol is frequently used in cases of tophi, frequent attack of arthritis or urolithiasis. [43]

Rasburicase is a potential alternative especially when allopurinol could not be used because of allergy or failure. Uricase reduces tophi volume and generates allantoin, which is easily excreted by kidneys, even in cases of chronic renal damage. [16] The involvement of kidney, frequent in tophaceous gout, in fact, makes difficult the use of allopurinol, whose excretion is mainly renal. Its dosage should be reduced or discontinued with consequent possible rise of uric acid and acute arthritic attack.

PEG-uricase, the long-acting form, seems to better control gout that non-pegylated form. The need for a daily administration and the increased probability of development of hypersensitivity with re-treatment make the use of non-modified rasburicase difficult in case of gout. [16]

PEG uricase accelerates potently tophi dissolution in 3 month, [46] while they remained stable or were partially eliminated with standard therapy. A trial, in which PEG-uricase was administered subcutaneously in patients with severe, refractory gout at doses between 4-24 mg in a single dose, has showed a reduction of uric acid pool until 21 days. [16]

Moreover, rasburicase has been effectively employed in transplanted patients with gout, where allopurinol in association with azathioprine or cyclosporine is contraindicated for the risk of leukocytopenia. $[47,48]$

Azathioprine is converted into mercaptopurine that is metabolized by xanthine oxidase into inactive compounds, so the concomitant enzyme inhibition by allopurinol causes a conspicuous increase of mercaptopurine bioavailability, myelotoxicity and risk of death. The association between allopurinol and immunosuppressive drugs, antineoplastic agent (6-mercaptopurine), anticoagulant dicumarol, thiazide diuretics, aluminium hydroxide, should be avoided or reduced doses of antineoplastic or immunosoppressive or other drugs should be used. It implies a major risk of unsuccessful control of tumor or transplant rejection.

A patient who requires the coadministration of this kind of drugs, risks a major toxicity, with consequent need of alternative drugs.

Although allopurinol is usually well tolerated, it may cause adverse effects that need a discontinuous use, in about $20 \%$ of patients. [49] Oxipurinol inhibits xanthine oxidase too and is an alternative to allopurinol, but an allergy to allopurinol is a contraindication to its use, owing to cross-allergies between them. [50]

Parental administration, risk of development of antibodies and the cell transformation in vitro stimulated by hydrogen peroxide [51] are still limits to using rasburicase. Currently it is employed in clinical trial where the selected patients with severe and tophaceous gout are intolerant, allergic, or not-responsive to standard therapy.

Future perspectives for gout are new xanthine oxidase inhibitors, including febuxostat, a nonpurine analogous, whose metabolism is mainly hepatic, and that reduces acid uric levels also in patients with renal impairment. [52]

\section{Advantages of rasburicase}

Rasburicase reduces uric acid levels within 4 hours both in paediatric and adults patients, so a 
mounting body of evidence confirms its effectiveness, tolerability and safety in the prevention and treatment of TLS. Table 4 reports some studies that demonstrate the efficacy of rasburicase.

Rasburicase is very efficacious in the reduction of the risk of renal damage during chemotherapy; it can dissolve uric acid crystals and can improve renal functions, permitting to continue chemotherapy. [54,55] The use of rasburicase is a good option, sometimes better than use of allopurinol in patients with severe acute hyperuricemia. Allopurinol is a structural analogous of hypoxanthine, inhibitor of xanthine oxidase, the last enzyme involved in uric acid synthesis pathway. It catalyzes the conversion of hypoxanyhine into xanthine and this latter into uric acid. During this reaction an active metabolite, deriving by enzymatic action on allopurinol, oxypurinol, inhibits xanthine oxidase and probably it is responsible for some adverse effects. (Table 5) Moreover, oxypurinol has an elimination half-life between 18 - 40 hours, depending on renal function (whereas $0.67-1.5$ for allopurinol) and its concentration increases after protracted administration. [56,57] So owing to its activity, its long elimination half- life and its urine excretion, it requires a dosage reduction, in case of renal impairment.

Allopurinol action is rather slow in reducing uric acid concentration, because acts on the new synthesis of uric acid, not on pre-existing uric acid. Hence, several days are necessary for before uric acid levels to decrease. The maximum effect appears within 14 days. [58]

Pharmacokinetics and pharmacodynamics of allopurinol is different according to aging: its renal excretion tends to decrease in elderly, [59] so the tolerance to its drugs may progressively decline.

The use of allopurinol may be complicated by the development of nephropathy, rarely reported in literature, [60] due to its mechanism of action that leads to an increase of hypoxanthine (more water soluble than uric acid) and xanthine (less water soluble than uric acid) concentrations and their precipitation in tubules. [61]

The incidence of acute hyperuricemic nephropathy has become rare using rasburicase. [62]

Adverse effects of allopurinol are skin rashes, pruritus, nephropathy, diarrhoea, headache that often require the discontinuation of the medication $(5 \%$ of patients). [49] A severe but rare side effect is hypersensitivity reaction with high-grade fever, bone marrow involvement, hepatic and renal toxicity, systemic vasculitis, exfoliative dermatitis. [63] This syndrome is more probable in patients who are retreated with allopurinol, after the discontinuation for skin rashes. [50] As explained, allopurinol action is delayed, because it acts on uric acid synthesis. In an oncologic emergency condition, such as TLS, we need a drug, as rasburicase, with rapid onset of action.

A comparison between rasburicase and oral allopurinol has showed the major efficacy of rasburicase in controlling hyperuricemia in children with a reduction in serum levels within 4 hours after the first dose
(-86\% rasburicase vs $-12 \%$ allopurinol). [14]

Moreover, rasburicase has different features that give some advantages, in comparison with allopurinol; many of these features are showed in table 6 . $[10,13,54,60]$

For these reasons, allopurinol remains an alternative when rasburicase is contraindicated (allergic reactions, glucose -6 - phosphate deydrogenase deficiency) or when TLS risk is low. [1]

Rasburicase is a good option also in comparison with hydration and alkalinization, that are the standard proceedings of TLS management.

Hydration, that should be started before and continued for several days after the end of chemotherapy, helps to dilute the excess of substances, to excrete them by an adequate urinary filtration rate and to prevent acute urate nephropathy, increasing intravascular volume. Hyperidration consists in a 2.5-3 litres $/ \mathrm{m}^{2} /$ day liquid administration. [41]

Hydration is a dangerous measure in patients at risk of volume overload and pulmonary edema: elderly or subjects with cardiovascular, renal or hepatic diseases.

The use of alkalinization, with infusion of sodium bicarbonate, and oral acetazolamide, during chemotherapy is justified because it facilitates clearance of uric acid and neutralizes the tendency to lowering of $\mathrm{pH}$ in patients with vomiting and diarrhoea.

It increases solubility and renal excretion of uric acid and xanthine, maintaining urinary $\mathrm{pH}$ between 7.0 and 7.3. Nevertheless, if $\mathrm{pH}$ exceeds 7.5, precipitation of calcium phosphate occurs, with worsening of hypocalcemic symptoms. Rasburicase does not require alkalinization [26] even though the use of this practice remains a doubt. It may increase acid uric clearance, but with a major risk of calcium phosphate precipitation [10] and alteration of blood $\mathrm{pH}$.

Neither patients treated with non recombinant urate oxidase nor those treated with rasburicase require dialysis. $[13,54]$

A retrospective comparison study between Allopurinol and Uricozyme ${ }^{\mathrm{TM}}$ has showed, in fact, that Uricozyme ${ }^{\mathrm{TM}}$ was more effective and rapid in controlling hyperuricemia, urea nitrogen and creatinine levels, eliminating need for dialysis. [54]

Urate oxidase in the prophylaxis and treatment of hyperuricemia and TLS reduces metabolic and renal complications and need for dialysis, which is more frequent in patients who receive allopurinol than rasburicase ( $16 \%$ vs $2.6 \%)$. [27] Other studies do not correlate need for dialysis with use of rasburicase. [64,65] In Goldman's trial, among patients treated with rasburicase, none required dialysis. [14] Among 100 patients with non Hodgink lymphoma, treated with rasburicase, during the first cycle of chemotherapy, none required dialysis and normalization of uric acid levels and control of creatinine levels were achieved. [66]

The absence of needing for dialysis is an advance in comparison with other regimes that do not use rasburicase, whose need is more remarkable. [67] 
A protective effect of rasburicase on uric acid induced-monocytes apoptosis has been recently demonstrated. The percentage of apoptosis decreases when cells, uric acid and urate oxidase are incubated together. [68]

\section{Adverse effects of rasburicase}

According to FDA, hypersensitivity is a risk during the treatment with rasburicase, but it's less probable with rasburicase than with non-recombinant urate oxidase.

Repeated use of rasburicase increases risk of hypersensitivity reactions: skin rashes $(1.4 \%)$, urticaria, bronchospasm $(<1 \%)$, dyspnoea, hypoxemia, anaphylactic shock $(<1 \%)$. [18] In these conditions, patients should be monitored during the treatment and the drugs should immediately be discontinued, associating an appropriate antiallergic therapy. Caution should be used in patients with a history of allergy.

A re-treatment has the same efficacy but title of antibodies antirasburicase (10-20\%) could increase, even though most of them are not neutralizing. [69] Antibodies develop about 1-6 weeks after administration. Often, the need for a re-treatment is rarer in neoplastic relapse, because this condition is more resistant to chemotherapy and so at lower risk of TLS development. [13]

Other adverse reactions are in order of decreasing incidence: fever $(6.8 \%)$, neutropenia with fever $(4 \%)$, respiratory distress $(3 \%)$, sepsis $(3 \%)$, neutropenia $(2 \%)$, mucositis $(2 \%)$, nausea $(1.7 \%)$, vomiting $(1.4 \%)$, headache $(0.9 \%)$, diarrhoea $(0.9 \%)$, and abdominal pain. [54]

PEG uricase has been associated with the following adverse reactions: a local injection site induration, precocious (within few hours) or tardive (8-9 days), the latter associated with generalized urticaria and arthralgia. In some patients, the development of a relatively low title of antibodies anti-PEG, not anti-uricase, was reported after 7 days. They reduced plasma uricase activity. [16]

Rasburicase is contraindicated in patients with glucose-6-phosphate dehydrogenase deficiency, because it may cause haemolytic anemia or methemoglobinemia. [70] Hydrogen peroxide $\left(\mathrm{H}_{2} \mathrm{O}_{2}\right)$, an oxidant by-product produced in the reaction catalyzed by uricase, is not neutralized because of this enzymatic lack. $[6,10]$

Moreover, rasburicase should be not administrated in pregnancy.

\section{Conclusion}

The increasing development of hyperuricemia, due to major incidence of cancer and intensive therapy, needs effective and safe drugs. Haematological malignancies and some bulky solid tumors are at high risk of developing hyperuricemia.

The acute nature of TLS requires, in fact, a quick approach because this condition severely worsens morbidity and mortality. The rapid action of rasburicase could permit to substitute some drugs, whose action is too gradual.
We have reviewed literature data reporting that rasburicase may be not only a potent and rapid approach for prevention and treatment of TLS, but also a drug useful in controlling hyperuricemia in chronic condition, such as gout. When urate-lowering therapy with allopurinol in tophaceous gout is contraindicated for allergy or intolerance or interactions with other drugs or refractory disease the use of rasburicase could be considered.

Rasburicase is a potent drug with potential advantages, that could be exploited even in pathologies, that differs from the classic indication of rasburicase. The long-action of PEG-uricase may be used also in patients with hyperuricemia deriving from inherited metabolic disorders. [9] (Table 7)

\section{Conflict of interests}

The authors have declared that no conflict of interest exists.

\section{References}

1. Cairo MS, Bishop M. Tumour lysis syndrome: new therapeutic strategies and classification. Br J Haematol. 2004; 127:3-11.

2. Choi HK, Mount DB, Reginato AM. American College of Physicians, American Physiological Society Pathogenesis of gout. Ann Intern Med. 2005; 143: 499 - 516.

3. Campion EW, Glynn RJ, Delabry LO. Asyntomatic hyperuricemia. Risks and consequences in the Normative Aging Study. Am J Med.1987; 82: 421-426

4. Lin KC, Lin HY, Chou P. The interaction between uric acid level and other risk factors on the development of gout among asyntomatic hyperuricemic men in a prospective study. Journal of Rheumatology. 2000; 27:1501 - 1505.

5. Leusmann DB. A classification of urinary calculi with respect to their composition and micromorphology. Scand J Urol. 1991;25:141-50.

6. Davidson MB, Thakkar S, Hix JK, et al. Pathophysiology, clinical consequences and treatment of tumor lysis syndrome. Am J Med. 2004; 116:546-554.

7. Kang DH, Nakagawa T, Feng L, et al. A Role for Uric Acid in the Progression of Renal Disease. J Am Soc Nephrol. 2002; 13:2888-2897

8. Scott GS, Hooper DC. The role of uric acid in protection against peroxynitrite-mediated pathology. Medical hypotheses. 2001; 56:95-100

9. Kelly SJ, Delnomdedieu M, Oliverio MI. Diabetes Insipidus in Uricase-Deficient Mice: A Model for Evaluating Therapy with Poly(Ethylene Glycol)-Modified Uricase. J Am Soc Nephrol. 2001;12:1001-1009.

10. Navolanic PM, Pui CH, Larson RA, et al. Elitek - rasburicase: an effective means to prevent and treat hyperuricemia associated with tumor lysis syndrome, a Meeting Report, Dallas, Texas, January 2002. Leukemia. 2003;17:499-514.

11. Leplatois P, Le Douarin B, Loison G. High-level production of a peroxisomal enzyme: Aspergillus flavus uricase accumulates intracellularly and is active in Saccharomyces cerevisiae. Gene. 1992; 122:139-145.

12. Bayol A, Capdevielle J, Malazzi P, et al. Modification of a reactive cysteine explains differences between rasburicase and Uricozyme $^{\mathrm{TM}}$, a natural Aspergillus flavus uricase. Biotechnol Appl Biochem. 2002;36:21-31.

13. Pui $\mathrm{CH}$, Mahmoud $\mathrm{HH}$, Wiley JM, et al. Recombinant urate oxidase for the prophylaxis or treatment of hyperuricemia in patients with leukemia or lymphoma. J Clin Oncol. 2001; 19:697-704

14. Goldman SC, Holcenberg JS, Finklestein JZ, et al. A random- 
ized comparison between rasburicase and allopurinol in children with lymphoma or leukemia at high risk for tumour lysis. Blood. 2001; 97:2998-3003.

15. Chua CC, Greenberg ML, Viau AT, et al. Use of polyethylene glycol-modified uricase (PEG-uricase) to treat hyperuricemia in a patient with non- Hodgkin lymphoma. Ann Intern Med. 1988; 109:114-117

16. Ganson NJ, Kelly SJ, Scarlett E. Control of hyperuricemia in subjects with refractory gout, and induction of antibody against poly(ethylene) glycol (PEG), in a phase I trial of subcutaneous PEGylated urate oxidase. Arthritis Res Ther. 2005; 8: R12

17. Ueng S. Rasburicase (Elitek): a novel agent for tumor lysis syndrome. Proc (Bayl Univ Med Cent). 2005; 18: 275-279.

18. Jeha S, Kantarjian H, Irwin D, et al. Efficacy and safety of rasburicase, a recombinant urate oxidase (Elitek TM), in the management of malignancy-associated hyperuricemia in pediatric and adult patients final results of a multicenter compassionate use trial. Leukemia. 2005; 19:34-38.

19. Oldfield V, Perry CM. Rasburicase. A review of its use in the management of anticancer therapy-induced hyperuricemia. Drugs. 2006; 66:529-545.

20. Hummel M, Buchheidt D, Reiter S, et al. Recurrent chemotherapy-induced tumor lysis syndrome (TLS) with renal failure in a patient with chronic lymphocytic leukaemia - successful treatment and prevention of TLS with low-dose rasburicase. Eur J Haematol. 2005; 75:518-521.

21. Liu CY, Sims-McCallum RP, Schiffer CA. A single dose of rasburicase is sufficient for the treatment of hyperuricemia in patients receiving chemotherapy. Leuk Res. 2005; 29:463-465.

22. Hutcherson DA, Gammon DC, Bhatt MS, et al. Reduced-dose rasburicase in the treatment of adults with hyperuricemia associated with malignancy. Pharmacother. 2006; 26:242-247

23. McDonnel AM, Lenz KL, Frei-Lahr DA, et al. Single-dose rasburicase $6 \mathrm{mg}$ in the management of tumor lysis syndrome in adults. Pharmacotherapy. 2006; 26:806-812.

24. Trifilio S, Gordon L, Singhal S, et al. Reduced-dose rasburicase (recombinant xanthine oxidase) in adult cancer patients with hyperuricemia. Bone Marrow Transplant. 2006; 37:997-1001.

25. Tarella C, Bono D, Zanni M, et al. Intensive chemotherapy in patients with lymphoma. Management of the risk of hyperuricemia. Contrib Nephrol. 2005;147:93-104.

26. Jeha S, Pui CH. Recombinant urate oxidase (Rasburicase) in the prophylaxis and treatment of tumor lysis syndrome. Contrib Nephrol. 2005;147:69-79.

27. Patte C, Sakiroglu C, Ansoborlo S, et al. Urate-oxidase in the prevention and treatment of metabolic complications in patients with B-cell lymphoma and leukemia, treated in the Société Française d'Oncologie Pédiatrique LMB89 protocol. Annals of Oncology. 2002; 13: 789-795

28. Patte C, Sakiroglu O, Sommelet D. European experience in the treatment of hyperuricemia. Semin Hematol. 2001; 38:9-12.

29. Leach M, Parsons RM, Reilly JT, Winfield DA. Efficacy of urate oxidase (uricozyme) in tumour lysis induced urate nephropathy. Clin Lab Haematol. 1998; 20:169-172.

30. Jankovic M, Zurlo MG, Rossi E, et al. Urate-oxidase as hypouricemic agent in a case of acute tumour lysis syndrome. Am J Pediatr Hematol Oncol. 1985; 7: 202-204.

31. Riccio B, Mato A, Olson EM, Berns JS, Luger S. Spontaneous tumor lysis syndrome in acute myeloid leukemia: two cases and a review of the literature. Cancer Biol Ther. 2006;5:1614-7

32. Rampello E, Fricia T, Malaguarnera M. The management of tumor lysis syndrome. Nat Clin Pract Oncol. 2006; 3:438-447.

33. Crittenden DR, Ackerman GL. Hyperuricemic acute renal failure in disseminated carcinoma. Arch Intern Med. 1977;137: 97-99.

34. Bilgrami SF, Fallon BG. Tumor lysis syndrome after combination chemotherapy for ovarian cancer. Med Pediatr Oncol. 1993; 21: 521-524.

35. Baeksgaard L, Sorensen JB. Acute tumor lysis syndrome in solid tumors-a case report and rewiew of the literature. Cancer Chemother and Pharmacol. 2003; 51:187-192.

36. Annemans L, Moeremans K, Lamotte M, et al. Pan-European multicentre economic evaluation of recombinant urate oxidase (Rasburicase) in prevention and treatment of hyperuricaemia and tumour lysis syndrome in haematological cancer patients. Support Care Cancer. 2003;11:249-257.

37. Pui $\mathrm{CH}$, Jeha $\mathrm{S}$, Irwin $\mathrm{D}$, et al. Recombinant urate oxidase (rasburicase) in the prevention and treatment of malignancy-associated hyperuricemia in pediatric and adult patients: results of a compassionate-use trial. Leukemia. 2001;15:1505-1509.

38. Macfarlane RJ, McCully BJ, Ferandez CV. Rasburicase prevents tumor lysis syndrome despite extreme hyperleukocytosis. Pediatr Nephrol. 2004; 19:924-927.

39. Pui $\mathrm{CH}$. Urate oxidase in the prophylaxis or treatment of hyperuricemia: the United States experience. Semin Hematol. 2001; 38(4 Suppl 10):13-21.

40. Vora A, Bhutani M, Sharma A et al. Severe tumor lysis sindrome during treatment with STI 571 in a patient with chronic myelogenous leucemia accelerated phase. Ann Oncol. 2002; 13:1833-1834.

41. Pession A, Barbieri E. Treatment and prevention of tumor lysis syndrome in children. Experience of Associazione Italiana Ematologia Oncologia Pediatrica. Contrib Nephrol. 2005;147:80-92.

42. Coiffier B, Riouffol C. Management of tumor lysis syndrome in adults. Expert Rev Anticancer Ther. 2007; 7:233-9

43. Richette P, Bardin T. Successful treatment with rasburicase of a tophaceous gout in a patient allergic to allopurinol. Nat Clin Pract Rheumatol. 2006; 2:338-342.

44. Arromdee E, Michet CJ, Crowson CS, O'Fallon WM, Gabriel SE. Epidemiology of gout: is the incidence rising? J Rheumatol. 2002; 29:2403-2406.

45. Moolenburgh JD, Reinders MK, Jansen TLThA. Rasburicase treatment in severe tophaceous gout: a novel therapeutic option. Clin Rheumatol. 2006; 25:749-752.

46. Baraf H, Kim S, Matsumoto AK, et al. Resolution of tophi with intravenous Peg-uricase in refractory gout. Arthritis Rheum. 2005; 52:S105.

47. Vogt B. Urate oxidase (rasburicase) for treatment of severe tophaceous gout. Nephrol Dial Transplant. 2005; 20:431-433.

48. Rozenberg S, Roche B, Dorent R, et al. Urate-oxidase for the treatment of tophaceous gout in heart transplant recipients. A report of three cases. Rev Rhum Engl Ed. 1995;62:392-394.

49. Wortmann RL . Recent advances in the management of gout and hyperuricemia. Curr Opin Rheumatol. 2005; 17:319-324

50. Bardin T. Current management of gout in patients unresponsive or allergic to allopurinol. Joint Bone Spine. 2004; 71:481-485.

51. Chu R, Lin Y, Reddy KC, et al. Transformation of epithelial cells stably transfected with $\mathrm{H}_{2} \mathrm{O}_{2}$-generating peroxisomal urate oxidase. Cancer Res. 1996 ; 56: 4846-4852.

52. Mayer MD, Khosravan R, Vernillet L, et al. Pharmacokinetics and pharmacodynamics of febuxostat, a new non-purine selective inhibitor of xanthine oxidase, in subjects with renal impairment. Am J Ther. 2005;12: 22-34.

53. Bosly A, Sonet A, Pinkerton CR, et al. Rasburicase (recombinant urate oxidase) for the management of hyperuricemia in patients with cancer: report of an international compassionate use study. Cancer. 2003; 98:1048-1054.

54. Pui CH, Relling MV, Lascombes $\mathrm{F}$, et al. Urate oxidase in prevention and treatment of hyperuricemia associated with lymphoid malignancies. Leukemia. 1997; 11:1813-1816

55. Wolf G, Hegewisch - Becker S, Hossfeld DK, et al. Hyperuri- 
caemia and renal insufficiency associated with malignant disease: urate oxidase as an efficient therapy?. Am J Kidney Dis. 1999; 34: E20

56. Appelbaum SJ, Mayersohn M, Dorr RT, Perrier D. Allopurinol kinetics and bioavailability. Intravenous, oral and rectal administration. Cancer Chemother Pharmacol. 1982;8:93-98.

57. Jaeger H, Russmann D, Rasper J, Blome J. Comparative study of the bioavailability and the pharmacodynamic effect of five allopurinol preparations. Arzneimittelforschung. 1982; 32:438-443

58. Schlesinger N. Management of acute and chronic gouty arthritis - Present state of the art. Drugs 2004; 64:2399-2416

59. Turnheim K, Krivanek P, Oberbauer R. Pharmacokinetics and pharmacodynamics of allopurinol in elderly and young subjects. Br J Clin Pharmacol. 1999. 48:501-509

60. Greene ML, Fujimoto WY, Seegmiller JE. Urinary xanthine stones - a rare complication of allopurinol therapy. New Engl J Med. 1969; 280:426-427

61. Klinenberg JR, Goldfinger SE, Seegmiller JE. The effectiveness of the xanthine oxidase inhibitor allopurinol in the treatment of gout. Ann Intern Med. 1965; 62:639-647

62. Moreau D. Pharmacological treatment of acute renal failure in intensive care unit patients. Contrib Nephrol. 2005; 147: 161-173.

63. Arellano F, Sacristan JA. Allopurinol hypersensitivity syndrome. A review. Ann Pharmacother. 1993; 27:337-343.

\section{Tables and Figures}

Table 1 Metabolic pathway of uric acid

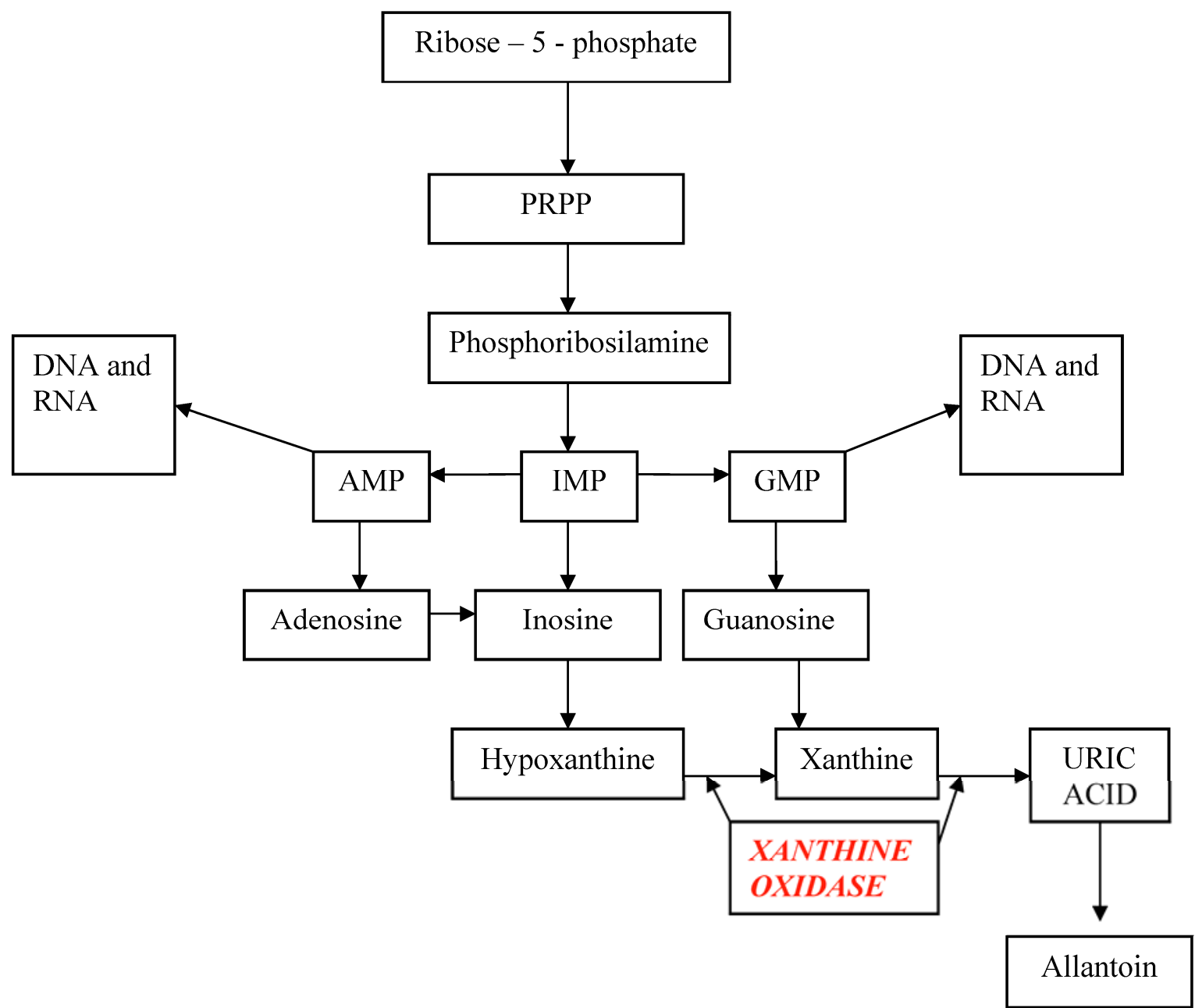

64. Hsu HH, Chan YL, Hung CC. Acute spontaneous tumor lysis presenting with hyperuricemic acute renal failure; clinical feauture and therapeutic approach. J Nephrol. 2004; 17: 50-56.

65. Agha-Razii M, Amyot SL, Pichette V, et al. Continuous veno-venous hemodiafiltration for the treatment of spontaneous tumor lysis syndrome complicated by acute renal failure and severe hyperuricemia. Clin Nephrol. 2000; 54:59-63.

66. Coiffier B, Mounier N, Bologna S et el. Efficacy and safety of rasburicase (recombinant urate oxidase) for the prevention and treatment of hyperuricemia during induction chemotherapy of aggressive non-Hodgkin's lymphoma: results of the GRAAL1 (Groupe d'Etude des lymphomas de l'Adulte Trial in Rasburicase Activity in Adult Lymphoma) study. J Clin Oncol. 2003; 21:4402-4406.

67. Stapleton FB, Strother DR, Roy S 3rd, et al. Acute renal failure at onset of therapy for advanced stage Burkitt lymphoma and B cell acute lymphoblastic lymphoma. Pediatrics. 1988; 82:863-869.

68. Bordoni V, Cal MD, Rassu M, et al. Protective Effect of Urate Oxidase on Uric Acid Induced-Monocyte Apoptosis. Curr Drug Discov Technol. 2005; 2:29-36

69. Pui CH. Rasburicase: A potent uricolytic agent. Expert Opin Pharmacother. 2002; 3:433-442.

70. Browning LA, Kruse JA. Hemolysis and methemoglobinemia secondary to rasburicase administration. Ann Pharmacother. 2005; 39: 1932-5 
Table 2 Metabolic unbalances in TLS

\begin{tabular}{c}
\hline Metabolic unbalances in TLS \\
\hline Hyperuricemia $\geq 476 \mu \mathrm{mol} / 1(\sim 8.0 \mathrm{mg} / \mathrm{dl})$ \\
\hline $\begin{array}{c}\text { Hyperphosphatemia } \geq 2.1 \mathrm{mmol} / 1 \text { (children) or } \\
\geq 1.45 \mathrm{mmol} / 1 \text { (adults) }\end{array}$ \\
\hline Hyperkalemia $\geq 6.0 \mathrm{mmol} / 1$ \\
\hline Hypocalcemia $\leq 1.75 \mathrm{mmol} / 1$
\end{tabular}

Table 3 Patients at high risk of TLS who could benefit by rasburicase

\begin{tabular}{|c|c|c|}
\hline Tumor factors & Patients factors & Biochemical factors \\
\hline High tumor burden & Hyperleukocytosis & High uric acid levels \\
\hline High tumor growth rate & Pre-existing renal impairment & High LDH levels \\
\hline $\begin{array}{l}\text { High sensitivity to chemotherapy, especially } \\
\text { during early treatment phase }\end{array}$ & Dehydration & High phosphoremia levels \\
\hline Advanced stage of tumor & Poly-pharmacology & Low $\mathrm{pH}$ of urine \\
\hline $\begin{array}{l}\text { Kind of tumor (haematological malignancies } \\
\text { more than solid tumors) }\end{array}$ & & High creatinine levels \\
\hline Lymphoma infiltration of kidney & & \\
\hline $\begin{array}{l}\text { Use of monoclonal antibodies and targeted } \\
\text { therapies }\end{array}$ & & \\
\hline
\end{tabular}

Table 4 Studies on rasburicase

\begin{tabular}{|c|c|c|c|c|c|c|}
\hline Authors & Year & Treatment plan & Patients & Effects on uric acid levels & Other effects & Toxicity \\
\hline $\begin{array}{c}\text { Pui et al. } \\
\text { (dose-validation } \\
\text { phase and ac- } \\
\text { crual phase) } \\
\text { Phase II trial } \\
\text { [13] }\end{array}$ & 2001 & $\begin{array}{l}\text { Rasburicase for 5-7 } \\
\text { days. Effective } \\
\text { dose founded is } \\
0.20 \mathrm{mg} / \mathrm{kg}\end{array}$ & $\begin{array}{l}131 \text { children, } \\
\text { adolescent } \\
\text { and young } \\
\text { adults with } \\
\text { leukaemia or } \\
\text { lymphoma, } \\
\text { high tumor } \\
\text { burden, high } \\
\text { acid uric and } \\
\text { creatinine } \\
\text { levels. }\end{array}$ & $\begin{array}{c}\text { After } 4 \text { hours, uric acid } \\
\text { decreased (from } 9.7 \text { to } 1 \\
\text { mg/dl in } 65 \text { patients; } \\
\text { from } 4.3 \text { to } 0.5 \\
\text { mg/dl in } 66 \text { patients). } \\
\text { After chemotherapy, } \\
\text { uricemia remained low. }\end{array}$ & $\begin{array}{l}\text { After } 1 \text { day, } \\
\text { creatinine } \\
\text { levels de- } \\
\text { creased and, } \\
\text { after } 6 \text { days, } \\
\text { returned } \\
\text { into normal } \\
\text { range }\end{array}$ & $\begin{array}{l}\text { Negligible toxicity, only a } \\
\text { single case of nausea and } \\
\text { vomiting. The case of } \\
\text { bronchospasm and hy- } \\
\text { poxemia might be related } \\
\text { to hypereosinophily, in- } \\
\text { duced by chemotherapy. } \\
\text { None of the patients } \\
\text { needed dialysis }\end{array}$ \\
\hline $\begin{array}{l}\text { Jeha et al. } \\
\text { (North Ameri- } \\
\text { can study - a } \\
\text { compassionate - } \\
\text { use trial) [18] }\end{array}$ & 2005 & $\begin{array}{c}\text { Rasburicase at a } \\
\text { dose of } 0.20 \\
\text { mg/kg for } 1-7 \\
\text { days. } \\
71 \text { patients re- } \\
\text { ceived additional } \\
\text { courses. }\end{array}$ & $\begin{array}{l}1069 \text { patients } \\
\text { (682 children } \\
\text { and } 387 \\
\text { adults) with } \\
\text { haematologic } \\
\text { malignancies } \\
\text { or solid tu- } \\
\text { mours at risk } \\
\text { of TLS or with } \\
\text { TLS }\end{array}$ & $\begin{array}{l}\text { Uric acid levels remained } \\
\text { low, also after chemo- } \\
\text { therapy, preventing ef- } \\
\text { fectively TLS. The effi- } \\
\text { cacy of rasburicase in the } \\
\text { treatment has been } \\
\text { demonstrated in all hy- } \\
\text { peruricemic adults and in } \\
98.5 \% \text { of hyperuricemic } \\
\text { children. }\end{array}$ & & $\begin{array}{l}\text { The adverse reactions in } \\
\text { single course were: head- } \\
\text { ache }(0.7 \%) \text {, rash }(0.4 \%), \\
\text { fever }(0.3 \%) \text {, vomiting } \\
(0.3 \%) \text {. Only some cases of } \\
\text { haemolityc anemia }(4), \\
\text { albunimuria }(1) \text {, allergic } \\
\text { reaction }(1) \text { and dyspnea } \\
(1) \text {, methemoglobinemia } \\
(2) \text {, hypoxia }(2) \text {, anaphylac- } \\
\text { tic shock }(1) \text {, rigor }(1) \text {, con- } \\
\text { vulsion }(1), \text { electrolyte ab- } \\
\text { normalities. } \\
30 \text { patients developed acute } \\
\text { renal failure, that required } \\
\text { haemodialysis. It was } \\
\text { caused by sepsis or com- } \\
\text { plications of chemotherapy, } \\
\text { only } 10 \text { cases by TLS or } \\
\text { hyperphosphatemia }\end{array}$ \\
\hline $\begin{array}{l}\text { Bosly et al. (in- } \\
\text { ternational } \\
\text { compassion- } \\
\text { ate-use study) } \\
\text { [53] }\end{array}$ & 2003 & $\begin{array}{l}\text { Rasburicase at } 0.20 \\
\mathrm{mg} / \mathrm{kg} \text { once a day, } \\
\text { for } 1 \text { to } 7 \text { days }\end{array}$ & $\begin{array}{l}219 \text { children } \\
\text { and adults at } \\
\text { risk to TLS }\end{array}$ & $\begin{array}{l}\text { In hyperuricemic pa- } \\
\text { tients, rasburicase low- } \\
\text { ered uric acid levels (in } \\
\text { adults from } 13.1 \mathrm{mg} / \mathrm{dl} \\
\text { to } 0.3 \mathrm{mg} / \mathrm{dl} \text { after treat- } \\
\text { ment; in children from } \\
11.3 \mathrm{mg} / \mathrm{dl} \text { to } 0.2 \mathrm{mg} / \mathrm{dl} \text { ) }\end{array}$ & & $\begin{array}{l}5 \text { patients need dialysis. } \\
\text { Adverse effects were: } \\
\text { headache }(1.8 \%) \text {, fever } \\
(1.4 \%), \text { rigors }(1.1 \%) \text {, aller- } \\
\text { gic reactions }(0.7 \%)\end{array}$ \\
\hline $\begin{array}{l}\text { Trifilio et al. } \\
\text { (retrospective } \\
\text { study) [24] }\end{array}$ & 2006 & $\begin{array}{l}\text { Single dose of } \\
\text { rasburicase at } 3 \mathrm{mg} \\
\text { and allopurinol, } \\
\text { hydration and } \\
\text { other supportive } \\
\text { therapy in } 36 \text { pa- } \\
\text { tients; additional } \\
\text { dose of } 1.5 \text { or } 3 \mathrm{mg} \\
\text { in } 6 \text { patient with } \\
\text { not controlled } \\
\text { hyperuricemia }\end{array}$ & $\begin{array}{l}43 \text { adults } \\
\text { patients with } \\
\text { cancer }\end{array}$ & $\begin{array}{l}\text { Both in single dose and in } \\
\text { double dose, rasburicase } \\
\text { lowered uric acid levels, } \\
\text { slower than higher dose }\end{array}$ & $\begin{array}{l}\text { After } 24 \\
\text { hours, } \\
\text { creatinine } \\
\text { levels de- } \\
\text { clined in } 39 \\
\text { patients and } \\
\text { raised in } 4 \\
\text { ones. }\end{array}$ & $\begin{array}{l}\text { No patients required dialy- } \\
\text { sis. }\end{array}$ \\
\hline $\begin{array}{l}\text { Associazione } \\
\text { Italiana Ema- }\end{array}$ & 2005 & $\begin{array}{l}\text { Rasburicase at } \\
0.15-0.20 \mathrm{mg} / \mathrm{dl}\end{array}$ & $\begin{array}{l}26 \text { paediatric } \\
\text { patients at }\end{array}$ & $\begin{array}{l}\text { Highly significant decline } \\
\text { of uric acid levels within }\end{array}$ & $\begin{array}{l}\text { Creatinine } \\
\text { levels nor- }\end{array}$ & $\begin{array}{l}\text { Well tolerated in all pa- } \\
\text { tients }\end{array}$ \\
\hline
\end{tabular}




\begin{tabular}{|c|c|c|c|c|}
\hline $\begin{array}{c}\text { tologia Oncolo- } \\
\text { gia Pediatrica } \\
\text { (AIEOP) Ex- }\end{array}$ & for 1-11 days & risk for TLS & $\begin{array}{c}\text { 24 hours in hyperurice- } \\
\text { mic and in }\end{array}$ & $\begin{array}{c}\text { malized } \\
\text { within } 5\end{array}$ \\
$\begin{array}{c}\text { days after } \\
\text { perience in Bo- }\end{array}$ & & $\begin{array}{c}\text { non-hyperuricemic pa- } \\
\text { tients. These values were }\end{array}$ & $\begin{array}{c}\text { the start of } \\
\text { rasburicase }\end{array}$ \\
\hline
\end{tabular}

Table 5 Mechanism of action of allopurinol

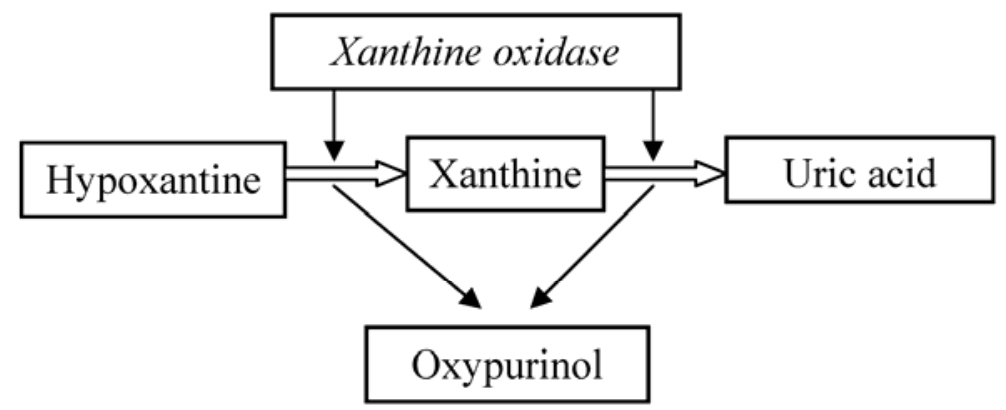

Table 6 Main features of allopurinol and rasburicase

\begin{tabular}{|c|c|}
\hline Allopurinol: a preventive uricogenesis agent & Rasburicase: an uricolytic agent \\
\hline $\begin{array}{l}\text { It competitively inhibits xanthine oxidase, so prevents further uric } \\
\text { acid synthesis }\end{array}$ & $\begin{array}{l}\text { It catalyzes the oxidation of already synthetized uric acid into allan- } \\
\text { toin }\end{array}$ \\
\hline $\begin{array}{l}\text { It does not directly alter acid uric levels, so its action is slower and } \\
\text { gradual, within } 24-48 \mathrm{~h} \text { and reaches a maximum after } 7-10 \text { days }\end{array}$ & Its action is faster in controlling uricemia, within $4 \mathrm{~h}$ \\
\hline It may increase creatinine levels & $\begin{array}{c}\text { It may reduce creatinine levels and urea nitrogen, by improving } \\
\text { renal function }\end{array}$ \\
\hline $\begin{array}{l}\text { It increases precursors of uric acid, such as xanthine, less soluble in } \\
\text { urine than uric acid. It may impair renal function and improve stone } \\
\text { formation. }\end{array}$ & $\begin{array}{l}\text { It does not require alkalinization, so calcium phosphate's stones } \\
\text { formation is less probable. }\end{array}$ \\
\hline $\begin{array}{c}\text { Its formulation is oral since } 1966 . \\
\text { Since } 1999 \text { a new intravenous formulation (not yet available in Italy) } \\
\text { was introduced in USA }\end{array}$ & An intravenous formulation is available \\
\hline $\begin{array}{l}\text { It needs an adjustment of doses if patient has renal impairment, } \\
\text { because its active metabolite, oxypurinol, is excreted in urine. }\end{array}$ & $\begin{array}{l}\text { No adjustment of doses is necessary if patient has renal or hepatic } \\
\text { impairment. In renal failure, allantoin may accumulate, but it is not } \\
\text { toxic. }\end{array}$ \\
\hline $\begin{array}{l}\text { It has drug-drug interaction with very common agents (chlorpropa- } \\
\text { mide, 6-mercaptopurine, azathioprine, dicumarol, cyclosporine, } \\
\text { thiazide diuretics) }\end{array}$ & No drugs interactions are referred \\
\hline
\end{tabular}

Table 7 Clinical uses of rasburicase

\begin{tabular}{|c|c|}
\hline & Jse of rasburicase \\
\hline \multicolumn{2}{|c|}{ Prophylaxis and treatment of TLS } \\
\hline \multirow[t]{5}{*}{ Tophaceous gout } & Allergy to allopurinol \\
\hline & Intolerance to allopurinol \\
\hline & $\begin{array}{c}\text { Interaction between allopurinol and other } \\
\text { drugs }\end{array}$ \\
\hline & Elderly \\
\hline & Renal failure \\
\hline \multicolumn{2}{|c|}{ Inherited metabolic disorders } \\
\hline \multicolumn{2}{|c|}{ Perspective use in condition with acute and severe hyperuricemia } \\
\hline
\end{tabular}




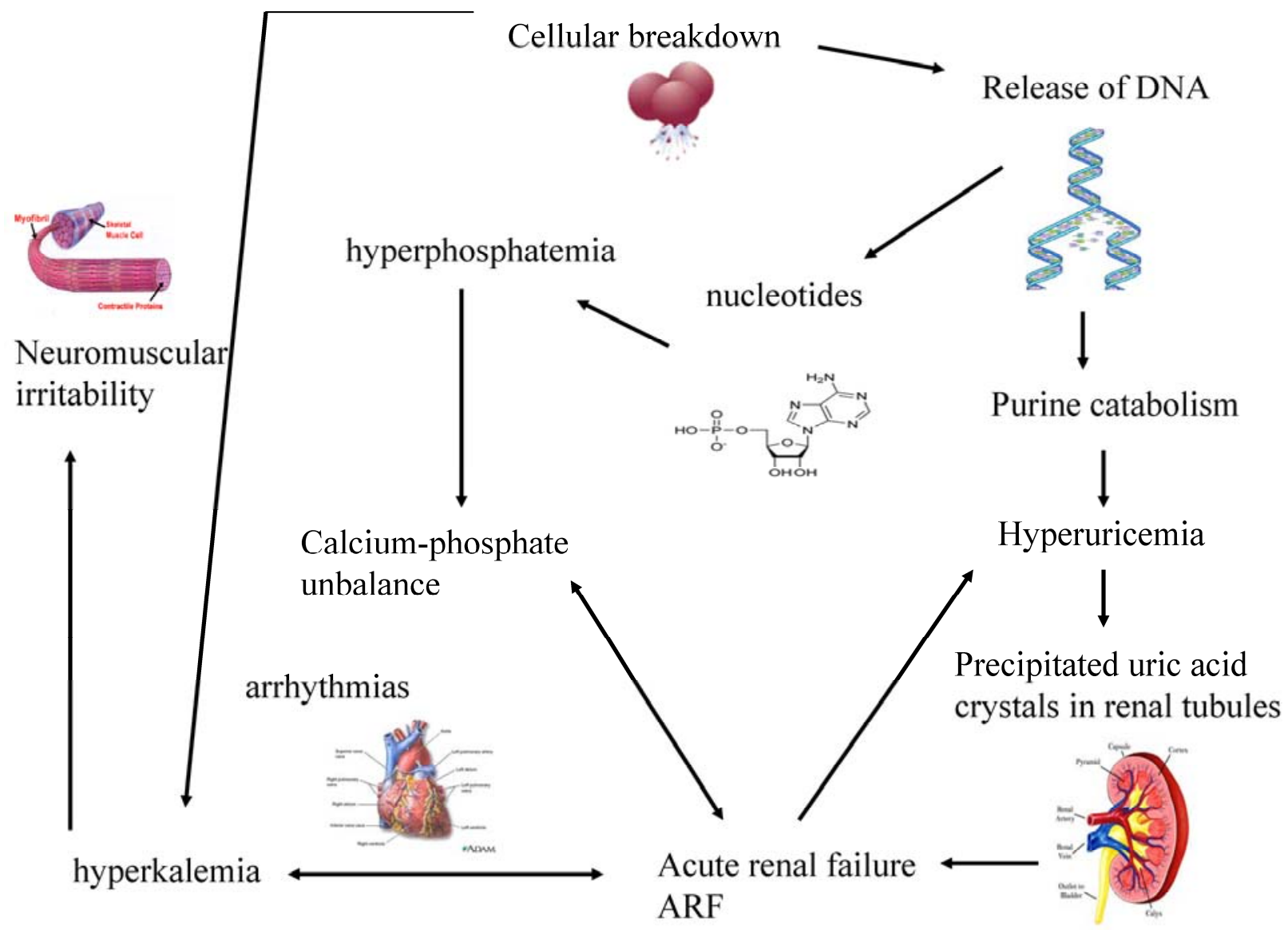

Figure 1 The systemic effects of cellular lysis and the consequent vicious circle that worsens renal functionality

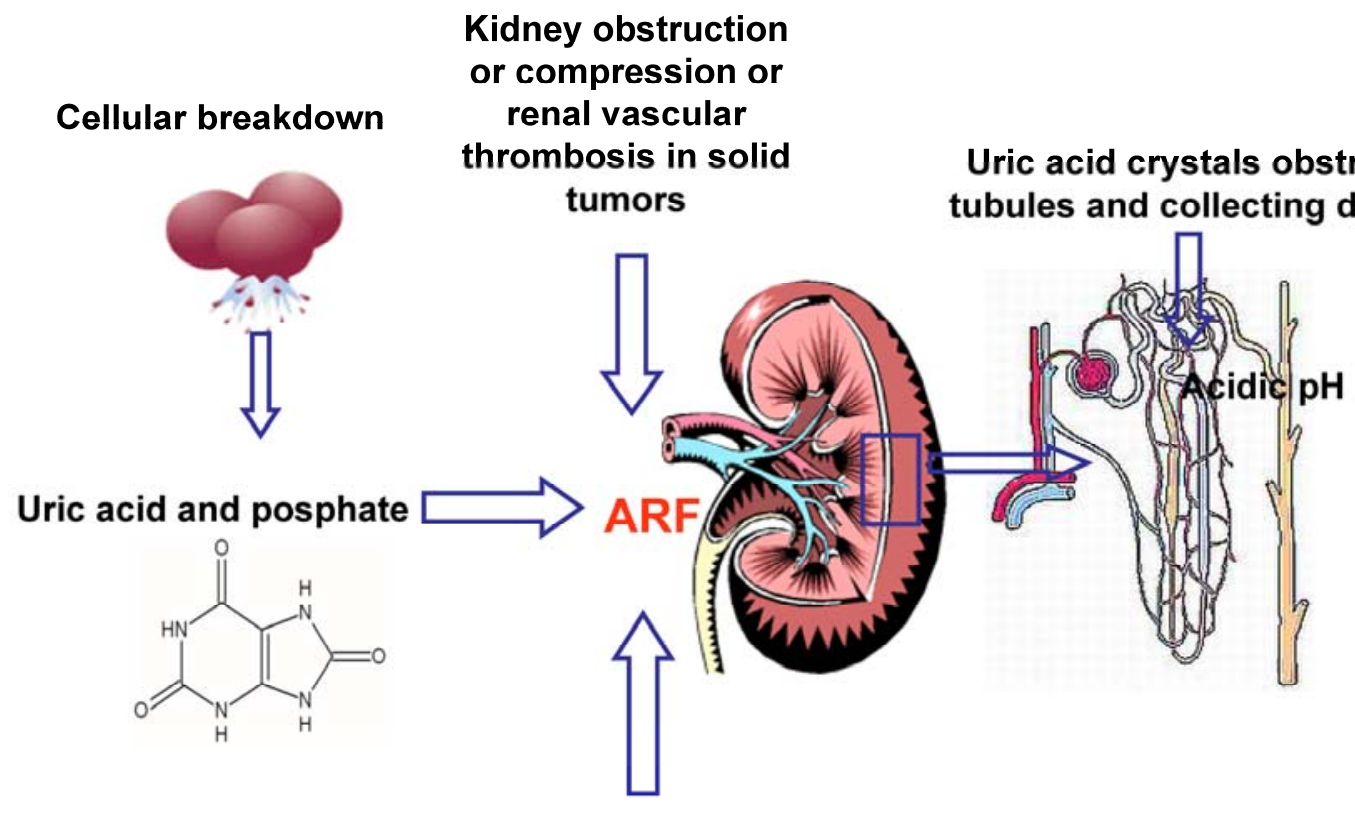

Chemotherapeutic, antibiotics, antiviral and antifungal drugs

Figure 2 Multifactorial pathogenesis of ARF (Acute Renal Failure) 